\title{
Note on Transliteration
}

The system of transliteration from Cyrillic is meant to be reader-friendly to someone who does not know Russian. When a name is already familiar in English in a conventional spelling-Meyerhold, Eisenstein, Tchaikovsky, Chaliapin, Chagallwe have retained that spelling. "E" at the beginning of a name is rendered as " $E$ " rather than as "Ye" - so Evreinov, not Yevreinov. The soft sign has been dropped from some names and words well known in the West, for example, from Gorky and Gogol, but not from Ol'ga, Bol'shoy, or Khar'kov.

\begin{tabular}{|c|c|c|}
\hline Cyrillic & System used in this book & Pronunciation \\
\hline $\mathrm{Aa}$ & $\mathrm{a}$ & father \\
\hline Бб & $\mathrm{b}$ & $\begin{array}{l}b \text { ank; (at the end of } \\
\text { words) to } p\end{array}$ \\
\hline Вв & $\mathrm{v}$ & $\begin{array}{l}\text { vet; towel; (at the end of } \\
\text { words) deaf }\end{array}$ \\
\hline Гг & $\mathrm{g}$ & $\begin{array}{l}\text { get; (at the end of words) } \\
\text { break }\end{array}$ \\
\hline Дд & $\mathrm{d}$ & $\begin{array}{l}\text { daddy; (at the end of } \\
\text { words) vet }\end{array}$ \\
\hline $\mathrm{Ee}$ & e & met; mitt; yeah \\
\hline Ëë & $\ddot{\mathrm{e}}$ & border; yore \\
\hline Жж & $\mathrm{zh}$ & vision; push \\
\hline 33 & $\begin{array}{l}\mathrm{z} \text { (except when it } \\
\text { indicates a German } s \text { ) }\end{array}$ & $z$ eal \\
\hline Ии & $\mathrm{i}$ & cheese; if \\
\hline Йй & $\mathrm{y}$ & unstressed vowel \\
\hline Кк & $\mathrm{k}$ & kept \\
\hline Лл & 1 & $\log$ \\
\hline Мм & $\mathrm{m}$ & mama \\
\hline $\mathrm{Hн}$ & $\mathrm{n}$ & no \\
\hline Oo & o & $\begin{array}{l}\text { (stressed) order; } \\
\text { (unstressed) artistic }\end{array}$ \\
\hline Пп & $\mathrm{p}$ & page \\
\hline
\end{tabular}


XVi | THE SOVIET THEATER

$\begin{array}{lll}\text { Рр } & \mathrm{r} & \text { rake } \\ \text { Сс } & \mathrm{s} & \text { miss } \\ \text { Тт } & \mathrm{t} & \text { ten } \\ \text { Уу } & \mathrm{u} & \text { spoon } \\ \text { Фф } & \mathrm{f} & \text { form } \\ \text { Хх } & \mathrm{kh} & \text { hah; ach } \\ \text { Цц } & \text { ts } & \text { its } \\ \text { Чч } & \mathrm{ch} & \text { chief } \\ \text { Шш } & \text { sh } & \text { shoe } \\ \text { Щщ } & \text { shch } & \text { fish chowder } \\ \text { Ьъ } & \text { omitted } & \text { no sound value } \\ \text { Ыы } & \text { y } & \text { phooey } \\ \text { ьь } & \text { omitted } & \text { no sound value } \\ \text { Ээ } & \text { é } & \text { vet; day } \\ \text { Юю } & \text { yu } & \text { you; suit } \\ \text { Яя } & \text { ya } & \text { yahoo }\end{array}$

Diphthongs

$\begin{array}{lcl}\text {-ай } & \text { ау } & \text { eye } \\ \text {-ый } & \text { y } & \text { its } \\ \text {-ий } & \text { y } & \text { even } \\ \text {-ия } & \text { iуa } & \text { triage } \\ \text {-ье } & \text { 'e } & \text { yeah } \\ \text {-ьи } & \text { 'i } & \text { yip }\end{array}$

